\title{
COMMENTS
}

\section{Global challenges of food safety for China}

\author{
Joseph J. JEN (凶) \\ College of Agriculture, California Polytechnic University, Las Vegas, NV 89141, USA
}

\begin{abstract}
Ever since the Melamine event, China has faced challenges of food safety both domestically and globally. With the economic development, the Chinese consumers are demanding high quality, nutritious, and safe foods from the food industry but are not willing to pay higher prices. The Chinese food chain system of mostly small and medium enterprises presents challenges to the government to monitor and implement food safety laws and regulations. The academia and media are learning to take on their responsibilities with some success. Discussions and potential solutions of the global challenges of the five pillars for the food safety in China are presented here.
\end{abstract}

Keywords food safety, challenges, food industry government, academia, media, consumer

\section{Introduction}

To say that China is facing a great many challenges in food safety is probably an under-statement. All the five parties responsible to food safety of the society ${ }^{[1]}$ are facing serious challenges. China has had a tremendous financial progress for the past two decades. As a result, consumers are demanding food products of more variety, more convenience, and low prices all at the same time. To meet these consumer demands of modern China, the food processing industries are producing more food products using non-traditional processing methods which has not been tested with time, thus, are more likely to have food safety problems.

Chinese culture in the past paid more attention to food security than food safety. Consumers are used to unsanitary food products may cause diarrhea problem particular when one travels to different locations of the country. It is not until 2008, when the Melamine caused infant formula made thousands of children hospitalized and death of infants $^{[2]}$ that the country as a whole started to pay attention to food safety.

Received January 1, 2017; accepted February 24, 2017

Correspondence: josephjjen@yahoo.com
The Chinese central government quickly published the first Food Safety Law of China in $2009^{[3]}$ without much consultations with scientists, industry, or consumers. It was proven that the law could not be implemented and must be revised. The Revised Food Safety Law was published in $2015^{[4]}$. It followed the laws established in advanced countries and is very comprehensive. The laws in advanced countries took into their country culture and is based mostly on sound scientific background after years of experience. Whether the new revised Food Safety Law in China can be implemented successfully in China is still a question mark. It is likely that the law needs further revision to fit the special cultural and today's environmental situations in China.

\section{Challenges}

Needless to say, among all people involved with food safety, the food industry must bear the major responsibility. Without produced safe food, it is not possible for the rest of the society to have safe food products to consume. With the quick economic development of China and the increased disposable income, the Chinese consumers are demanding high quality, nutritious, tasty and low priced food products. The challenges to the Chinese food industry is that the industry has been based on high volume, low profit production, often do not have cost of food safety program involved in the production. For example, green and organic food products involving non-thermal processing technology are highly desirable by many consumers yet the consumer do not want to pay higher prices for them. One way to deal with the situation is vertical integration of controlling seeds, feeds, use of pesticides, antibiotics, quality and safety of the total production chain. A few big domestic companies have done that which led to very large top globally ranked food companies in China in recent years. Many global multinational companies have formed joint ventures with these domestic companies, some through merger and new investment, and supplied advanced science and technology to the Chinese companies. Nevertheless, this only solved a small part of the 
challenges in China. China is a 20:80 food industry: 20\% production is from large companies and $80 \%$ production is from small and medium enterprises. How to have proper food safety culture sink into these small and medium enterprises is a major challenge. Given the culture in China, the food industry must partner with the government to deal with these challenges.

China's revised Food Safety Law ${ }^{[4]}$ enacted in October, 2015 is intended to strength the regulation of food safety in China and enhance oversight during the supply chain. Like in other issues, however, the challenge is not in the setting regulations but in the implementation. The regulation of food law in China is facing a wide range of potential hazards such as absorption of soil contaminants, illegal additives in the production process, and unethical business practices like selling fake or expired items. The regulators also have to face a diverse and fragmented (and thus chaotic) domestic food industry with over 35000 small and medium-sized food processing enterprises ${ }^{[5]}$. The biggest challenge to the government is the lack of qualified inspectors. Inspectors without food safety trainings often caused more problems and distrust from the consumers and industry. An urgent need of the government is to implement a "food safety train the trainer" program at the center level for all provinces and city regulators. These trained inspectors can go back to their respective provinces and cities and train provincial city and township regulators, then to the village level personnel. Without such a program, it is difficult to see how the food safety laws can be implemented in China, nor how the government can regain the trust of the Chinese consumers. These training courses must be carried out by a consumer trusted third party program such as the Bor S. Luh Food Safety Research Center of the Shanghai Jiao Tong University.

The third pillar of food safety responsibility lies with the academia. Unfortunately, due to the current academia system, publication on named journals is the only desire of the Chinese university professionals. It led to most of the published research papers are laboratory based and have no possibility of scale up for food industry usages. There are over 300 higher learning institutes have BS or MS degrees in food quality and food safety in China. There is no standard curriculum for these programs and the trained graduates cannot be used by the food industry without additional training by the industry. It seems that the Ministry of Education needs to consult with food industry and government agencies to set up a standard degree in Food Safety to produce graduates that can serve the society. The International Union of Food Science and Technology has recently developed a certified standard food safety curriculum which can be consulted.

The media in China has matured fast in recent years. The push by the Chinese Institute of Food Science and Technology of gathering media and scientists to discuss food safety issues face to face have paid big dividends. Most major traditional media in China has food safety reporters and are writing sensible reports in newspapers and television programs. There has been a book published by reporters to guide new reporters on reporting food safety events ${ }^{[6]}$. The challenge to the media is the frequent changes and influx of new reporters with little scientific knowledge. May be a short one day special media training program can be developed by institute such as the Bor S. Luh Food Safety Research Center and be held annually to assist the media to meet this challenge. The major challenge for China is the widespread use of internet chat programs. Many people write about incorrect food safety information without any scientific base and without sources of information. Unfortunately, this is a problem not only in China, but for the rest of the world. Few scientists are starting to work on using the social media to spread correct food safety information ${ }^{[7]}$.

According to a Pew Global attitude survey, over $71 \%$ of Chinese people considered food safety as big problem in 2015. There was few research and survey of Chinese consumer behavior, attitudes and handling of food safety problems in China. Bai and Gong ${ }^{[8]}$ summarized the situation in China, and noted that the consumers realized that they do not have adequate knowledge of handling meats and poultry products at home. The major challenge is how to make consumers believe in correct food safety education in China. There is an urgent need of establishing an authority third party voice in Food Safety in China. Given the Chinese culture of respecting Academicians, may be this body need to find a way to establish such a voice for the Chines society.

\section{Conclusions}

China is facing many difficult challenges in food safety. Each segment of the five-responsible party of the country has their unique challenges. However, given the five thousand years of history with resilience, and the modern society desire of high quality life, I believe the Chinese can find ways to overcome these challenges. The key of success rests on two elements: (1) Education: Only education can lead to understanding of the food safety knowledge and build cooperation between the five segments of the society, and (2) Transparency: Only through transparency can build trust among each other. Food safety culture is built one step at a time. China has made great progress toward the understanding of food safety in a short time. It is the continued dedication toward an overall food safety culture for China to meet the global challenges of the Chinese that is waiting for us in the future

\section{References}

1. Jen J J. The shared responsibility of food safety. In: Jen J J and Chen J 
S, eds. Food Safety in China: Past, Present and Future. Beijing: China Science and Technology Press, 2017: 1-9

2. Chen J S. What can we learn from the 2008 melamine crisis in China? Biomedical and Environmental Sciences, 2009, 22(2): 109-111

3. Standing Committee of the National People's Congress. Food Safety Law of the People's Republic of China. 2009

4. Standing Committee of the National People's Congress. Food Safety Law of the People's Republic of China (2015 Revision). 2015

5. Meng S. The development of Chinese food industry. In: Jen J J and Chen J eds. Food Safety in China: Past, Present and Future. Beijing:
China Science and Technology Press, 2016: 32-51

6. Jiang X J, Zhu H J, Hu Y L, Zhong K B. Food Safety Reports Handbook. Beijing: People's Publishing House, 2014

7. Liu R, Pieniak Z, Verbeke W. Food-related hazards in China: consumers perception of risk and trust in information survey. Food Control, 2014, 46: 291-298

8. Li B, Gong S. Consumer knowledge, attitude and behavior toward food safety. In: Jen J J and Chen J eds. Food Safety in China: Science, Technology, Management and Regulation. Oxford: Wiley-Blackwell Inc., 2017 